\title{
The Christie Hospital and Holt Radium Institute, Manchester
}

GITUATED in the outskirts of Manchester, the Christie Hospital and Holt Radium Institute, which was opened in 1933, presents certain features interesting not only from the medical aspect, but also from the point of view of organization of radio-therapy for malignant disease.

The present institution (Fig. 1.) is the result of the fusion of two much older hospitals ; it is one of the largest units of its kind in Europe, and is only exceeded in size by a few American institutions a long start over many other centres where organization was at first more haphazard. The Christie Cancer Hospital had a longer history. It developed gradually from a cancer home for incurables to an active unit concerned with the surgical treatment of malignant diseases. It then became apparent that expansion was essential, and in 1933, under the chairmanship of F. P. Nathan, deputy-lieutenant of the County of Lancashire, the scope of the work of both units

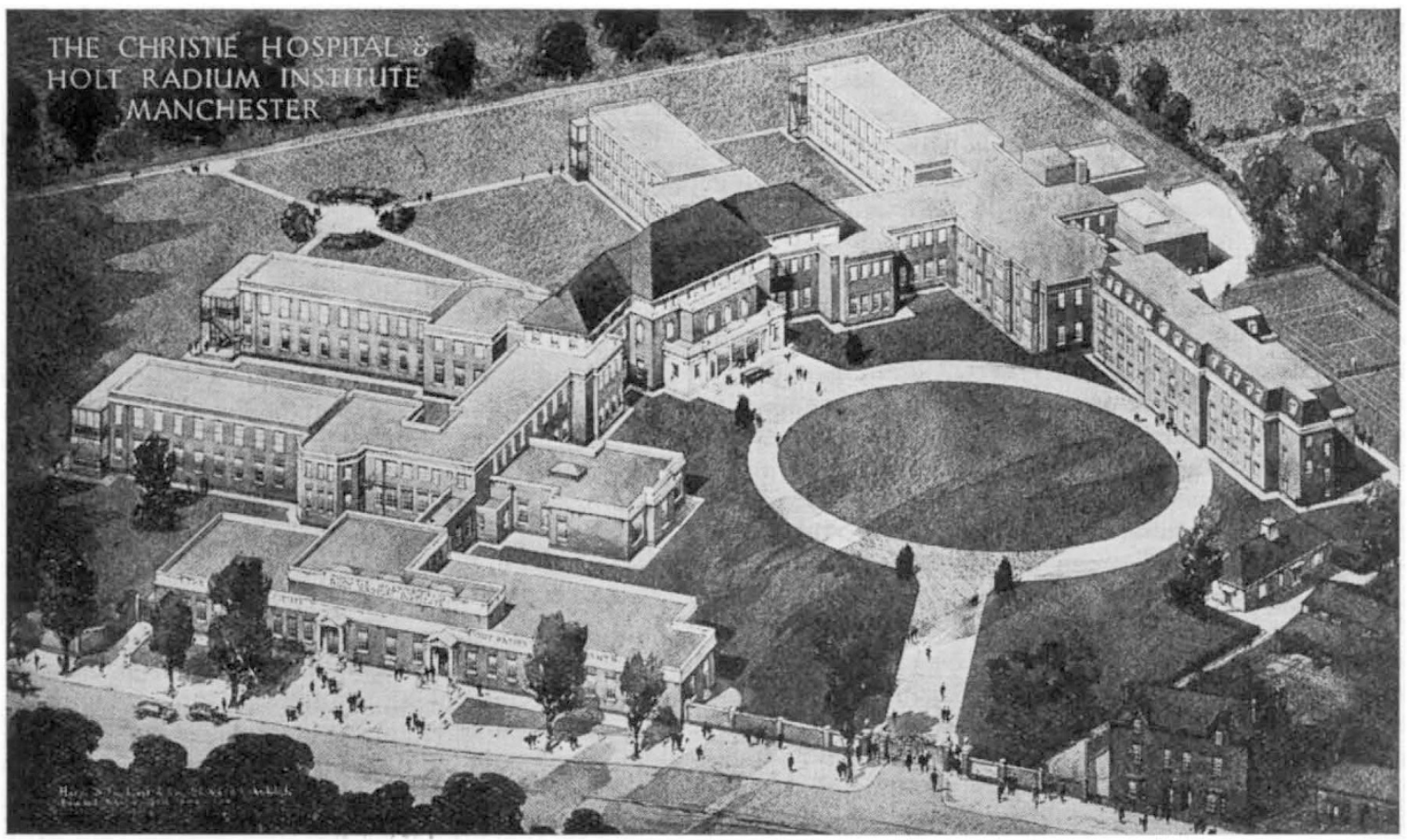

of similar type. Although the main purpose of the unit is the treatment of patients suffering from malignant disease, much experimental work is done concomitantly to advance the scientific practice of radio-therapy, and to study the action of radiation on living tissue.

Little need be said about the history of the Institute. The old Manchester Radium Institute founded in 1915 within the confines of the Manchester Royal Infirmary took independent existence in 1921, owing to the generosity and foresight of Sir Edward Holt, at one time lord mayor and a freeman of Manchester. From the beginning, this Institute, under the guidance of the first director, Dr. A. H. Burrows, maintained the principle that radiation therapy should be centralized as an independent specialty. In consequence, Manchester had was vastly increased by fusion and removal to the present spacious buildings.

More than six grams of radium are held at present; part of this is owned, and part is loaned from the National Radium Commission. The bulk of the radium is in the form of needles and tubes, with in addition just over one gram in solution for the preparation of radon. With this amount of radium in use, extensive protective devices for the health of workers have had to be developed. From the time the radium leaves the safe, which has protecting walls of $6 \mathrm{in}$. of lead, until the moment of insertion into the patient, the radium needles remain encased in lead, although in the interval they have been threaded, prepared, sterilized and transported from room to room. 
Speaking generally, present-day radium methods consist either of implantation of radium contained in hollow platinum needles into and around malignant growths, or of the application of radium, suitably mounted, superficially to such growths. The former method, implantation technique, is analogous to surgical procedures and requires asepsis and anaesthetics. On the other hand, for radium used superficially, a special laboratory has been developed which combines to some extent the features of a dental workshop with those of a sculptor's studio. Here plaster casts of the tumour-bearing area are made and appliances modelled on these to carry the radium and to fit each patient exactly.

The X-ray Department consists at the moment of a suite of four rooms, each containing an X-ray tube energized at 250 kilovolts. These plants were designed and built by the Research Department of Metropolitan-Vickers Electrical Co., Ltd., and constituted, when first designed, a new departure in the application to medical work of continuously evacuated X-ray tubes and rectifying valves. At the present time, there is being installed a 500 kilovolt unit of similar design. The units are operated with the anti-cathode at ground potential; two advantages accrue from this. First there is the ability to use direct water-cooling of the target from the mains, and second there is the advantage that the high tension is completely removed from the treatment room. Rotation of the head of the tube carrying the target (anticathode) is achieved through a geardriven joint between optically flat steel surfaces. For actual treatment, the emergent beam is defined by applicators which also rotate round the tube, interlocked with the rotation of the target.

The linkage between power units and tubes is of some interest. There are in all four $250 \mathrm{kv}$. tubes, and two $250 \mathrm{kv}$. generators. The design is such that each generator can be connected to any or all of the tubes, through one or other of a pair of high-tension leads. To achieve this, each tube has a high-tension change-over switch through which it can be linked to either generator or to earth. The main high-tension leads occupy a special overhead duct behind the treatment rooms. Normal running is usually two tubes to each generator, but there are no fewer than seventy different combinations available for various contingencies. The installation was designed therefore in such a way that any one plant or any one tube could be isolated and repaired in the event of breakdown with the absolute minimum of interference with the general running of the Department.

The radiological staff consists of a group of whole-time therapists, and two physicists. The

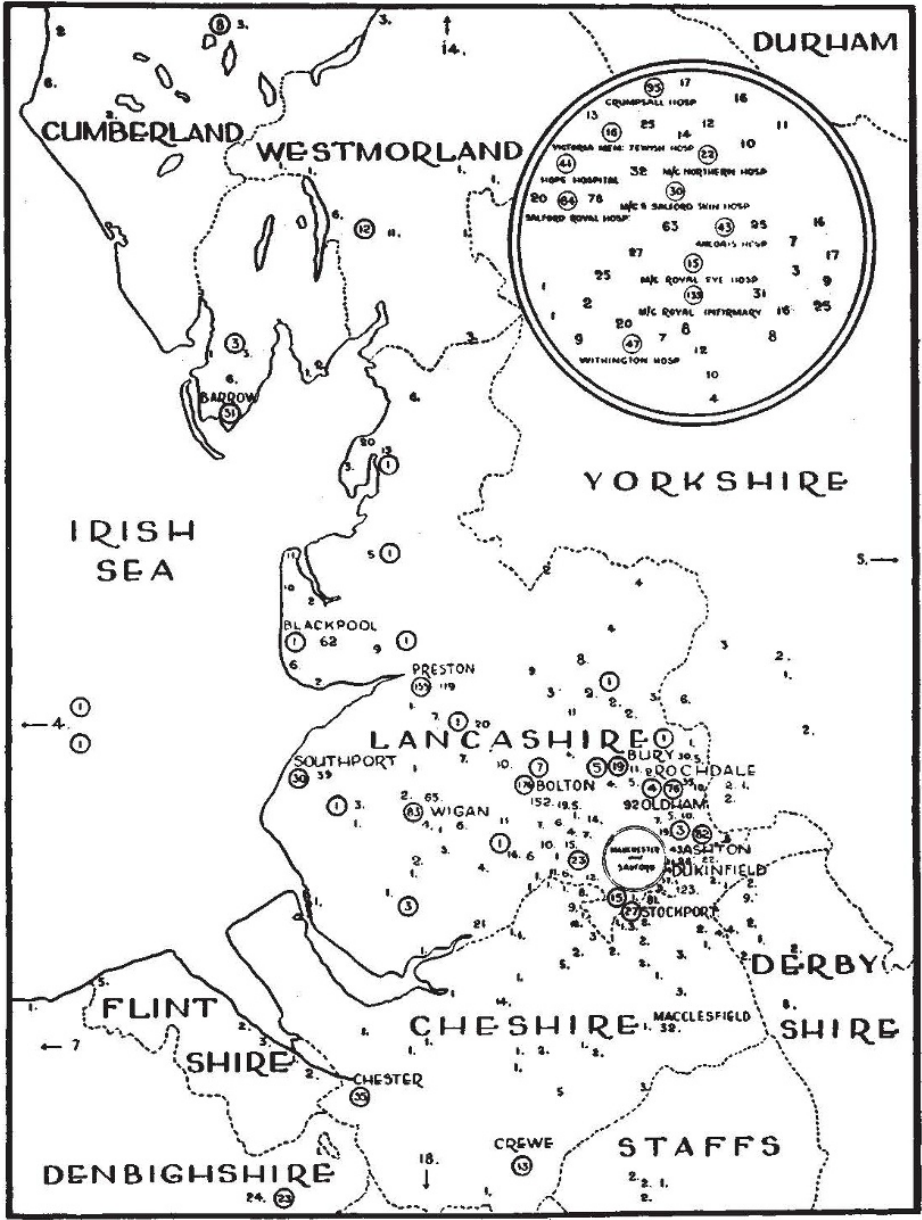

AREAs for WHICH RADIUM THERAPy SERVICE IS PROVIDED. FIGURES INDICATE NUMBER OF PATIENTS REFERRED FROM EACH TOWN IN 1937. HOSPITALS RECEIVING RADIUM SERVICE, $O$. INSET MAP : DETAILS OF THE MANCHESTER AND SALFORd AREa. medical and surgical work is dependent on an honorary visiting staff. There are also various auxiliary services. The radiological work is divided amongst the team in such a way that each therapist, in addition to general work, takes over a special small field in which he can become expert and in which he can develop new techniques.

During the last five years, this team has made a number of useful contributions to the science of 
radio-therapy, particularly in relation to the development of accurate systems of dosage.

To the physically minded, it may seem almost incredible that radium therapy should have been practised until recently on no sound quantitative basis; yet such was the case. Radium dosage was described in terms of the amount of radium used, and for accurate information was relatively meaningless. It was obviously essential to have a unit which states the amount of radiation absorbed at any point, be it in tumour growth or in skin. Some years ago the Manchester School evolved a clinically practical unit of measurement of gamma radiation, selecting for this the roentgen, the internationally accepted unit of X-radiation. This choice was made in order to bring these two essentially similar therapeutic agents to comparable terms. The suitability of the roentgen as a unit of gamma ray therapy was recognized at the recent International Congress of Radiology.

In X-ray therapy also, treatment methods have been open to severe criticism, in that they consisted of a mass of empirical techniques depending on a variety of variable factors, such as so-called 'air dosage', skin tolerance doses, and so forth. The Manchester School has contributed to the clarification of the situation by the development of methods of treatment in terms of accurately measured tumour dosage.

There are three fields in which this knowledge of dosage has proved of immense value. First, information can now be obtained on the tolerance of normal tissue, especially skin, to the effects of radiation, and the importance of the 'time factor' in that respect can be studied. Next, it is at last becoming possible to group tumour growths relatively accurately in accordance with their particular radiosensitivity. Lastly, the value of accurate measurement in the experimental work of the new Research Laboratories of the Institute is inestimable. Research on the biological effects of radiation covers an immense field, but as C. M. Scott has pointed out, the value of much of it has until now been entirely vitiated by the absence of a quantitative outlook.

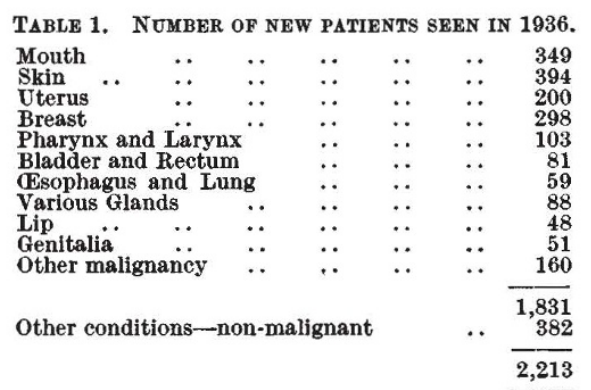

Cancer is still, after war and the toll of the roads, one of civilized man's most serious menaces, and an inevitable question in considering the work of an institute such as this is as to the results of treatment, and as to whether real advance is being achieved. A very brief review is given, therefore, of the part which radiation plays in the treatment of malignant disease. The scope of radiation therapy can be summarized by an analysis of the types of cases treated at the Institute (Table 1).

Of these numbers, how many are likely to be cured? Table 2 indicates in round figures the achievement of the methods employed in 1932 as assessed to-day (non-malignant group excluded).

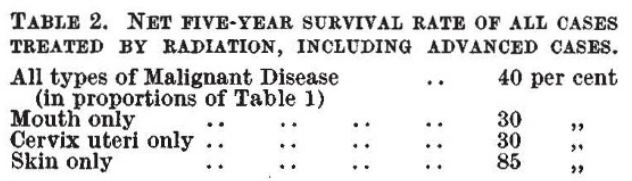

It will be observed that the figures in Table 2 include the survival rate of all cases treated, whether in the early or advanced stages. A more striking illustration of what can be achieved by radiation therapy is seen in Table 3 , from which the very advanced cases have been excluded-a table which at the same time points to the importance of early treatment of malignant disease.

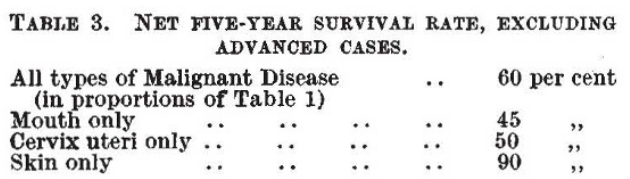

Summarizing, it may be said that, while malignant disease remains one of the most serious of diseases, nevertheless something quite definite can be achieved by the methods employed in an institute such as the one under description. The number of patients treated now yearly exceeds 2,000. As estimated from the work of previous years, at least 50 per cent of these will certainly be alive and well three years after, 40 per cent five years after, and unlikely to develop recurrence of their tumour. Unfortunately, many patients at the time they are first seen can only be assisted in a palliative way, the disease having been allowed to progress too far. If we consider the value of treatment in relation only to the earlier lesions, then we find that some 60 per cent of all cases may be expected to be alive and well in five years' time.

As will be seen from Table 1, radio-therapy is at present a method of treatment only applicable to a proportion of all cancer cases, and the number of such cases in even a large population is relatively low. In a population of 100,000 there are probably between 50 and 60 cases of cancer per annum which should be treated by radio-therapy. On this basis, a unit with extensive equipment and a considerable medical staff must serve a very wide area to reach its highest effectiveness. It is 
estimated that the 2,000 new cases seen annually represents the sifting of cases from a population of approximately 6,000,000. The proportion of cases sent in for treatment from each district tends to vary inversely with the distance from the

TABLE 4.

\begin{tabular}{|c|c|c|c|c|}
\hline Year & $\begin{array}{c}\text { No. of patients } \\
\text { referred from } \\
\text { civic area** } \\
\text { (Population } \\
1,039,740 .)\end{array}$ & $\begin{array}{c}\text { No. referred } \\
\text { per 100,000 } \\
\text { population. }\end{array}$ & $\begin{array}{c}\text { No. of patients } \\
\text { referred from } \\
\text { immediately } \\
\text { surrounding } \\
\text { areaf. (Popula. } \\
\text { tion 1,663,860.) }\end{array}$ & $\begin{array}{c}\text { No. referred } \\
\text { per 100,000 } \\
\text { population. }\end{array}$ \\
\hline 1931 & 465 & 44 & 362 & 21 \\
1932 & 434 & 41 & 365 & 21 \\
1933 & 474 & 45 & 462 & 27 \\
1934 & 496 & 47 & 736 & 44 \\
1935 & 572 & 55 & 794 & 49 \\
\hline Increase over 5 years-25 per cent & Increase over 5 years-133 \\
per cent & \\
\hline
\end{tabular}

* Civic area includes the cities of Manchester and Salford.

t Surrounding area is the south-east quarter of Lancashire (excluding Manchester civic area), bounded by the line, Cheshire border, Warrington (exclusive), Preston (inclusive), Yorkshire border.

centre. Thus in the immediate local area (Manchester, Salford and Stockport), practically all cases come for consideration regarding treatment, while in the periphery of the zone served, a smaller fraction is referred unless steps are taken to increase it. This situation is demonstrated by
Table 4, which also shows the results of the measures adopted by the Institute to reach patients in the surrounding area.

This improvement in the availability of treatment to patients has been achieved by the development in connexion with the Institute of clinics not only in Manchester in its own hospitals, but also in a large number of voluntary hospitals of towns in the area served (see accompanying map). Treatment clinics are also held, but in a more limited number of such outside hospitals. There the simpler cases are dealt with, while those more complex are brought for treatment to the central unit where the facilities are greater. In the same way the Institute has entered into agreements with City and County Health Authorities by which cases of cancer in their control are seen, and if suitable for radio-therapy are treated.

In conclusion, there are many indications that as national organization for the treatment of cancer evolves, it may be necessary to develop it along lines similar to those now accepted for the treatment of tuberculosis, that is, along modified State service lines. In this case, the unit and the organization described above may prove to have been in some respects a prototype.

\section{Recent Developments in the Geology of the U.S.S.R.}

\section{By Prof. N. N. Gornostayev*}

$\mathrm{T}$ HE successive Five Year Plans in the Soviet Union have been accompanied by a vigorous development of geological science, and new mineral wealth is being discovered almost daily by the 6,000 geologists who are employed in prospecting over the whole vast area of the U.S.S.R. Soviet deposits of oil, coal, peat, iron, manganese, gold, potash salts and phosphates, are among the largest in the world.

In 1913 the known coal deposits of Russia comprised but 3.2 per cent of the world's resources, as estimated by the Twelfth International Geological Congress. At the Seventeenth Congress held in Moscow last year, the estimated coal resources of the Soviet Union were found to be seven times greater than in 1913, comprising $1,654,361$ million tons, or nearly 21 per cent of the world's coal reserves.

In addition to the Donetz Basin, which yielded 87 per cent of the coal mined in Russia in 1913, large coal deposits have been discovered in Kazakhstan, Siberia and the Far East. The coal deposits of European Russia now comprise only

* Revised and abridged by Dr. G. W. Tyrrell from an article entitled "Soviet Geology" received from the Soviet Union Year Book Press Service.
$9 \cdot 1$ per cent of the total resources of the U.S.S.R. This more uniform distribution of coal resources has made widespread industrialization much more feasible.

The iron ore deposits of the Soviet Union are now known to be five and a half times greater than was estimated in 1913. The reserves of oil are fourteen times greater than was estimated in 1905. Oil fields have been found along the entire Urals range, and prospecting is in progress on the vast Siberian plains. It is possible that Siberia will be found to contain some of the richest oil deposits in the world. Incidentally, Siberian oil is the oldest known, as it is found in Cambrian formations.

It is now established that about 83 per cent of the world's known resources of potash are concentrated in the U.S.S.R., and these resources are being steadily augmented by new discoveries. More than 73 per cent of the world's manganese ore reserves are contained within the Soviet Union. The huge deposits of apatite found in the Kola Peninsula have doubled the world's resources of phosphates. 